\title{
Thiazide Diuretic
}

National Cancer Institute

\section{Source}

National Cancer Institute. Thiazide Diuretic. NCI Thesaurus. Code C49185.

Any benzothiadiazide derivative or other thiazide-like agent with diuretic and antihypertensive activity. Thiazide diuretics inhibit the sodium-chloride transporter in the distal tubule in the kidneys, thereby suppressing sodium and chloride reabsorption from the distal convoluted tubules (DCT) and increasing the excretion of sodium, chloride, potassium and water. In addition, thiazide diuretics decrease excretion of calcium and uric acid. These agents cause vasodilation possibly by activating calcium-activated potassium channels in vascular smooth muscle and inhibiting various carbonic anhydrases in vascular tissue. 